\section{ALGUNAS CUESTIONES MERCANTILES ANTE EL DERECHO}

\section{Salvador R. Perrotta}

Professor Catedrático da Faculdade de Direito e Ciências Sociais de Buenos Aires

Desde ya me apresuro a aclarar que no presentaré problemas intrincados de derechô, ni complejas cuestiones de técnica jurídica. Por el contrario analizaré descarnadas de toda presentación exterior las cuestiones que a mi juicio revelan la necesidad de una previsión legislativa inmediata. Haré práctica mercantil y no derecho comercial.

Y agregaré aún algo más. "Hay materias en el derecho" se dice - "en las cuales el jurista desempeña, por imposición de la naturaleza de las mismas, una función menos brillante, diríamos, que en otras en las cuales puede aspirar a asumir en la elaboración de las normas de derecho la mayor parte de las materias que integran lo que acostumbramos llamar derecho mercantil o comercial. En él por lo común, es de los propios intereses en juego que ha surgido y sigue surgiendo el material de renovación y perfeccionamiento de las reglas existentes, correspondiendo, entonces, al legislador o al jurisconsulto solamente la tarea de ir dando forma a las exigencias del ambiente, encauzando las nuevas instituciones en el marco de las existentes. Así, la letra de cambio, el cheque, la limitación de la responsabilidad en las sociedades, la representación del capital de éstas en títulos negociables, la prenda sin desplazamiento y tantas otras reformas introducidas en el derecho comercial tradicional, no han sido obra de abogados o de profesores de derecho, sino de comerciantes $o$ industriales asociados por la necesidad de facilitar el desenvolvimiento de sus negocios. No es esa, por lo demás, una característica exclusiva del denominado derecho comercial. Se extiende a todo lo que podríamos nombrar con el derecho de la contratación, pues en todo el campo del derecho convencional el ingenio de los interesados es el que ha ido creando nuevas modalidades de las figuras jurídicas tradicionales. Al legislador y al jurista no le ha correspondido después más que la tarea de amoldarlas al régimen existente.

Eso, es precisamente, lo que ha ocurrido en la compra-venta y las muchas variedades que ella presenta tanto en la materia comun-

$$
-349-
$$

mente considerada comercial, como en la que es mantenida dentro del derecho común o civil, la cual es una de las tantas razones que fundamentan la pretensión de hacer desaparecer, respecto de ese contrato como de todos los demás, la separación de las dos grandes ramas tradicionales, que a su vez formaría parte de un derecho único del patrimonio" ${ }^{(1)}$. Así se produce la regulación jurídica del comercio y el estudioso del derecho debe aspirar a secundar el esfuerzo de los interesados en la creación de normas exigidas por actuales necesidades.

O dicho en otros términos, la regulación del comercio mediante normas que como poder legislador sanciona el Congreso, surge de las necesidades del ambiente, de la práctica o de las costumbres. Hay algunas cuestiones resueltas en virtud de esas tres causas, pero que no tienen en la ley comercial previsión ni solución alguna, y sabemos bien que la legislación adelanta a veces, muy pocas o sigue a remolque de los acontecimientos o de los hechos económicos. No estamos en 1857, ni en 1862 , ni en 1889 , años en que se sanciona y reforma el Código de Comercio Argentino ( $\left.{ }^{2}\right)$. - Hoy en 1950, se presentan multitud de problemas legislativos en que el interés público aparece estrechamente unido al de la justa regulación de la vinculación jurídica entre particulares que deben ser regidas por un Código. -

Tenemos así ante nosotrós un panorama de realidad económica y social que plantea problemas y exige soluciones. Dentro de ellos hay algunos que correspondiendo al derecho mercantil reclaman solución legislativa impostergable. Se ha dicho así, con razón, que "El cuadro que presenta hoy la legislación comercial argentina es bien distinto del que ofrecía en 1889, al sancionarse el código de comercio vigente, y está más alejado todavía del que podría observarse, en 1873 al emprenderse la reforma del 1862, como consecuencia de la sanción del Código Civil en 1869. El profundo sacudimiento político sufrido por el mundo entero a raíz de la guerra de 1912 a 1918, ha originado no pocas reformas legislativas en el orden comercial, tanto en las naciones a las que tocó en su suerte ser actores, como en las que, aún desde el lugar de espectadores sufrieron más o menos directa o indirectamente las consecuencias de lo que algunos llegan, hoy, cuatro lustros más tarde, a calificar, por más de una razón, como regresión hacia el aislamiento medioeval. De los diversos sectores de la legislación, uno de los que con mayores motivos tenía que sentir los efectos, era el relacionado con el comercio,

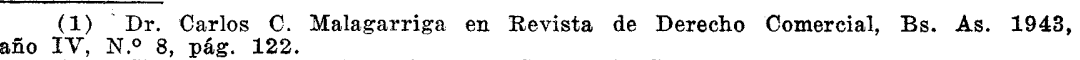
(2) Cincuentenario de la Reforma al Código de Comercio de la Repáblica Argentina, 23 - R. D. $1 .{ }^{\circ}$ Vol. 
en su más amplia acepción, porque es el que realiza el contacto y la relación entre las naciones, en el orden patrimonial y pecuniario, al propio tiempo que es la avanzada de contacto en el ordem espiritual, y al que más directamente llegó el calor de la hoguera, como si fuere el edificio lindero al que se incendia".

"Por los demás, es necesario convenir que por el desarrollo de nuestro país, y por el lugar que ocupa en el actual estado económico, estamos ya en el deber de crear paulatinamente nuestro derecho comercial propio, sin preocuparnos de que por este camino nuestras leyes sean o no idénticas a las que la mayoría o minoría de otros países, que también las tienen distintas por razón de sus propias necesidades, precisamente la misma razón que justifica la sanción necesidades, precis
de las nuestras.

Decir esto, no significa menospreciar el mérito que puedan tener las leyes extranjeras o las ideas de los pensadores que les han dado forma y redación. Todo lo contrario; significa señalar la cordura y la prudencia que es lo que más debemos analizar para valorarlas; en el método de la elaboración de las leyes, para dictar las nuestras que respondan y sean eficaces para lo que necesitamos.

De esa manera en que insensiblemente han entrado las sanciones de nuestro Poder Legislativo, sin perseguir un deliberado propósito de crear el Derecho Comercial Argentino, es consecuencia, en el hecho, que asistimos hoy a un proceso de formación de un derecho que va tomando los contornos de una fisonomía propia y nacional. Debemos tener la pretensión que así suceda, y que ese derecho se forme no tanto por las concordantes de la legislación comparada, sino por ellas y su concordancia con nuestro medio ambiente y con el camino que toma nuestro país en su progreso". $\left({ }^{3}\right)$.

Es que, desde 1946, se perfila en nuestro país una transformación en la estructura económica en cuanto a su fase industrial y comercial que reclama su cabida en los cuadros legislativos.

Tenemos en primer lugar, el principio jurídico de la limitación del riesgo, que viene aplicándose en el derecho mercantil con excelentes resultados; la práctica, ha comprobado que la limitación de los riesgos en los negocios sin dañar los intereses de los acreedores favorece en general toda clase de empresa. Animados acreedores, ciantes e industriales por las esperanzas de realizar ben comercapitales puestos al servicio de una iniciativa, la audacia acompaña la certeza de no arriesgar toda la fortuna y su acción no se ve parali-

(3) Mario A. Rivarola. Tratado de Derecho Comercial Argentino, t. I, Introducción; 5 zada por el temor de comprometer en los azares de un negocio toda una posición económica labrada quizás despues de muchos años de trabajos e innumerables fatigas. $\left({ }^{4}\right)$.

Como consecuencia de ello ha surgido la idea de limitar la responsabilidad de un comerciante en su giro, solo al capital comprometido, creando la llamada "Empresa Individual de Responsabilidad Limitada". -

La Cámara de Comercio de Buenos Aires en 1940 ya se dirigía al Congreso pidiendo que se dictara una ley sobre esa materia ("). - Debo advertir que en Inglaterra y en Alemania existen desde hace mucho tiempo, sociedades limitadas de un hombre solo, pues se llega a la conclusión de que hay una necesidad psicológica en ciertos individuos que prefieren trabajar aislados antes que en sociedad. $\mathrm{Al}$ no existir una ley que le permita a un hombre por si a constituir una sociedad de responsabilidad limitada, se han visto obligados estos comerciantes que desean trabajar en tal sentido a formar sociedades con fraude de la ley. De ahí surgió la necesidad de dar solución legal al problema, sin los trastornos que se observan en la práctica cuando alguien utiliza a prestanombres. Esa realidad no se debe olvidar y hay que permitir a la persona que quieve limitar su responsabilidad el poder hacerlo sin necesidad de eludir la ley.

Pero se dirá cuales son las ventajas que reportaría la reglamentación legislativa de este asunto? A solo que se ahonde el problema, aparecen sus conveniencias. Así, favorece la iniciativa privada, evita la burla de la ley y el funcionamiento de sociedades ficticias cuyos capitales se han concentrado en una sola mano; ampara, como decía, a todos los hombres que no se avienen por su carácter o por su temperamento a unir sus esfuerzos y sus capitales a los de los demás y para quienes, este tipo de empresa abriría amplios horizontes a sus actividades.

Es innegable la moderna orientación en materia de restricción de la responsabilidad en el campo de las obligaciones jurídicas: el beneficio de inventario en la aceptación de la herencia, el abandono en el derecho marítimo, las sociedades de Responsabilidad Limitada y la reciente concepción sobre ente individual de responsabilidad limitada, pendiente de sanción legislativa en el Congresso, son exponentes de esa tendencia. Nada obsta pues, a que esa restrición se extienda también a la empresa individual que constituiría una nueva modalidad de empleo de capitales en el comercio y en la industria

Juan C. Sorondo. La responsabilidad en las sociedades de responsabilidad limitada.
Bs. As. 1940. Pág. 11 (Publieac. del Seminario de la Fac. de Derecho de Bs. As. Cur Prefacio del Dr Francisco Orione. 
Se evitarían así los espectáculos de ver a un comerciante que, deseando limitar su responsabilidad a una pequeña parte de su fortuna en un negocio, busca un prestanombre amigo o pariente que le sirve para aparecer asociado con él y actúa en realidad individualmente, con una responsabilidad limitada en base a una sociedad de las que admiten dicha limitación $\left(^{6}\right)$.

No debe olvidarse que las empresas de este tipo han tenido franco éxito en Inglaterra y en Alemania constituídas generalmente para apoyar el fomento comercial, cuando la industria objeto de la sociedad, presupone un riesgo de capital y resulta necesario limitarlo. Agregaré que las instituciones profesionales se han pronunciado también sobre este asunto; la 5. ${ }^{\text {a }}$ Conferencia Nacional de Abogados de Santa Fe 1940, en su resolución 7. declaró que: "es conveniente instituir en nuestra legislación como persona de existencia ideal la empresa individual de Responsabilidad Limitada" con el concepto de que "una persona física puede fundarla y responder con el capital que le asigne como patrimonio separado por las obligaciones derivadas de la explotación" ( 7 .

El Primer Congreso de Derecho Comercial constituído por juristas, profesores, expertos y magistrados, reunido en Buenos Aires en 1940 bajo los auspicios de la Universidad de Buenos Aires, en su resolución 18 declaró: "que conviene propiciar la institución legal de la empresa unipersonal con responsabilidad limitada" $(8)$

Existen incluso, proyectos de leyes muy completos $\left({ }^{9}\right)$, de tal modo que, es de esperar una saludable reacción que convierta en sanción legislativa esta necesidad.

\section{III}

El comercio internacional alcanza en el curso de este siglo un desarrollo inusitado facilitado por la rapidez y seguridad de las comunicaciones y la posibilidad de transportar grandes cantidades de mercaderías $\left({ }^{10}\right)$. La transformación se ha operado sobre todo en las grandes velocidades buscadas por todos los intereses vinculados al comercio, con lo que se impulsa y facilitan las transacciones. Aunque en un futuro próximo la Aeronavegación supere y remplace el transporte marítimo, por ahora este sigue siendo el más importante y económico en el comercio internacional. Las instituciones del derecho

pág. 418. Primer Congreso Nacional de Derecho Comercial. Actas; Bs. As. 1940, t. II, (7) Actas, pág. 444.
(8) Actas, t. II, pág.

G. Ball Lima, ob. cit. pág. 143-145. W. Arecha en Revista Derecho Comercial.
Bs. As. 1942. Año III. N. 6. pá. 123. Diputado M Oscar Rosito (Ćamara Diput

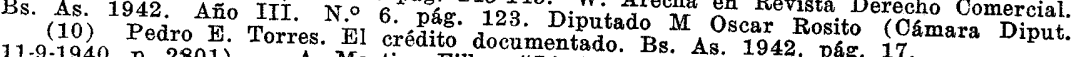
11-9-1940, Pedro E. Torres. El crédito documentado. Bs. As. 1942, pág. 17.
p. Martins Filho: "Limitação da Responsabilidade". comercial han tenido siempre la elasticidad requerida para el progreso de los negocios y frente a un nuevo aspecto de las transacciones se han suministrado satisfactoriamente las bases jurídicas para organizarlo en forma adecuada a la realidad y conveniente para la economía.

A ello se suman las complicaciones originadas en el comercio exterior particularmente marítimo, por las guerras de 1914, 1939 (hundimientos); bloqueos; prohibiciones; escasez de materias primas, de envases y de bodegas etc. y quizás también - aunque en menor grado - ciertos empeoramientos de la moral comercial perturbando así, el ambiente de confianza internacional; todo lo cual ha hecho surgir una nueva institución: el crédito documentado; regido hoy por normas y prácticas mercantiles como las aprobadas en Viena en 1933 por la Cámara de Comercio Internacional $\left.{ }^{(11}\right)$.

El Comité de Bancos de la Capital Federal sometió a la Asociación de Bancos de nuestro país, 17 reglas que merecieron la aprobación correspondiente, expresando la última de ellas: "Los usos y costumbres establecidos en las normas anteriorse se considerarán incorporados a toda orden de crédito precedentemente del extranjero en cuanto no fuesen expresamente modificados por dicha brden".

También se pronunció en el sentido de sancionar prácticas obligatorias la Conferencia de Montevideo de 1941 para las asociaciones americanas de comercio y producción.

La 2. ${ }^{\text {a }}$ Conferencia Nacional de Abogados reunida en Córdoba en 1926 y la $1 .^{\text {a }}$ Conferencia de Abogados de la Ciudad de Buenos Aires de 1943, dictaron igualmente la necesidad de una ley sobre la materia de carácter imperioso, afirmando que "la situación actual del comercio mantiene esa urgente necesidad pues el crédito documentado sólo se rige por normas bancarias que no llenan debidamente esa finalidad".

Como es lógico se trata en el caso de proteger y ayudar al comerciante argentino frente a los importadores extranjeros.

Pero, en que consiste este crédito?

La forma más usual de su empleo en el comercio se produce cuando, un comprador que debe recibir la mercadería conviene con un banco que se obligue ante el remitente a pagarle una suma determinada contra la presentación de documentos representativos de la mercadería, garantizando ésta al Banco la reintegración de lo pagado, por parte del comprador.

Ocurre a veces que esa obligación la cumple el Banco por medio de otro Banco, el que se limita a ejecutar la obligación del Banco

(11) Juan Roth. "Fl problema del crédito documentado" en Regista de Derecho
Comercial, Buenos Aires, 1943, Pág. 7 a 55. 
principal o a actuar en nombre del mismo o añadir su propia responsabilidad, tres situaciones diferentes y de distinta naturaleza jurídica para ese otro Banco que toma el nombre de Banco notificador.

Esa operación que sinteticamente acabo de explicar es conocida con el nombre de crédito documentador.

"Ninguna ingerencia se atribuye al Banco acreditante en la ejecución del contrato originario que liga al ordenante (comprador) y a beneficiario (vendedor). La función del Banco se limita a cumprir a nombre propio la convención celebrada con el ordenante y a su vez el Banco compromete con el beneficiario, o sea, el pago de una suma de dinero contra la presentación de documentos capaces de representar simbólicamente la mercadería y de tranferir su dominio.

\section{IV}

"La existencia de la gran industria y del gran comercio, ya concentrado en un país para abastecer al mundo, ya diseminado en varios paises para satisfacer necesidades comunes sólo se explica por la posibilidad de agrupar grandes capitales dedicados a una misma especulación industrial o comercial y con una dirección central común".

La "acción" es la institución jurídica que ha permitido esa concentración de capitales base fundamental de la civilización mecánica ${ }^{(12)}$.

En la actualidad se practica una nueva modalidad: las acciones de voto multiple o plural que escapan a toda reglamentación legal y cuya práctica se difunde ante el silencio del código.

Con ella, es posible disponer de más de un voto, facilitando el manejo de la sociedad y acordando las siguientes ventajas:

$10^{\circ}$ - Permitir la concentración comercial e industrial.

2. ${ }^{\circ}$ - Garante a los fundadores la permanencia de su dirección e influencia asegurando de tal modo la posibilidad de una gestión continuada e uniforme, y la permanencia de una orientación en la empresa.

$3 .^{\circ}$ - Justifica una retribución al mérito personal del fundador.

$4 .^{\circ}$ - Se allanan las dificultades que plantean la ausencia de los accionistas especialmente de los pequeños.

Se impone por lo tanto la sanción de leyes que reglamenten su emisión y mecanismo.

En el Brasil conforme al texto del artículo 141 de la ley de 1891 sobre sociedades, ésta institución no habría sido admitida.

(12) I. Winizky. Acciones de roto privilegiado. Buenos Aires, 1936.
Mazeaud $\left({ }^{13}\right)$ sostiene que dicha disposición las prohibe, princique estaría ratificado por el decreto 21.536 de 1932 .

po que estario virtud artículo $30^{\circ}$ de dicho decreto.

\section{CONCLUSION}

Resumiendo todo lo expuesto podemos sentar las siguientes premisas:

a) La regulación jurídica del comercio debe responder a las exigencias del momento y a las necesidades del ambiente;

b) En Argentina y Brasil tres instituciones mercantiles practicadas y reconocidas por los usos reclaman imperiosamente una sanción legislativa ya sea por la reforma íntegra del Código de Comercio o mediante leyes especiales: la Empresa Individual de Responsabilidad Limitada, el Crédito documentado y las acciones de Voto Múltiple.

Esperemos que así suceda para bien del progreso jurídico-económico de las Naciónes.

\section{RELATÓRIO E PARECER}

Relator: HERNANI ESTRELLA

O Prof. SALVADOR R. PERROTTA, catedrático da Faculdade de Direito e Ciências Sociais de Buenos Aires, apresenta à consideração dêste Congresso o trabalho ALGUNAS CUESTIONES MERCANTILES ANTE EL DERECHO, no qual, após deduzir lúMERCANTIL̃óes sôbre o progressivo e constante evolver da exu等 berante vida mercan as normas de direito positivo, que deveriam discipliná-la, sugere o estudo e ulterior consagração nos direitos mercantís argentino e brasileiro das seguintes instituiçõos:

$1^{\text {a }}$ - Emprêsa individual de responsabilidade limitada;

$2 .^{\mathrm{a}}$ - Crédito bancário confirmado;

$3 .^{a}$ - Ações de voto múltiplo ou plural.

societés de capitaux: Paris 1929. 2.a ed. p. 201.

(13) Le vote privile
(14) ob. cit. p. 65. 


$$
-356-
$$

$\mathrm{Na}$ motivação que constitui pressuposto lógico-jurídico da conclusão, o autor lembra, com muita exatidão e propriedade, que, atento o caráter normativo do direito, êste deve, tanto quanto possivel satisfação às exigências da realidade objetiva. E, em nenhuma outra ordem de relações, mais do que na esfera do tráfico, no mundo dos. negócios, o jurista desempenha uma função, quase diríamundo dos mente receptiva, eis que, na elaboração das normas de direito positivo, deve se ater às aquisições da prática contratual, dos usos e costumes, que vêm a ser, afinal, o fato gerador da norma e a própria razão de sua existência.

Dessarte, e no que tange a cada uma das instituições lembradas. na comunicação em exame, cumpre não olvidar:

I) O progressivo alagamento do conceito de limitação do risco (latu sensu), tem sido aplicado com excelentes resultados e do mais variado modo. Assim, nas sociedades individualistas, através das formas comanditárias, acionárias e, ulteriormente, limitadas; de igual maneira e para o comércio marítimo, o abandôno, o seguro, e, ainda, as cláusulas de franquia ou de exclusão da responsabilidade.

A generalização dessa tendência transpôs já o âmbito do direito mercantil, vindo a repercutir até mesmo no campo do direito público, como parece suceder, relativamente, à responsabilidade direito público, administração, que, embora não liberta de todo em todo, cuida construí-la sob bases que se inspiram no propósito de mitigar a extensão dessa mesma responsabilidade.

E, porém, no comércio, pela própria álea a que está exposto, onde essa preocupação teve e vem tendo a mais larga aplicação. Todavia, aquela conhecida inércia jurídica, tão bem analisada por Jhering faz com que o direito positivo só evolve lentamente, daqui que os instrumentos técnicos, as fórmulas por êle oferecidas não correspondam, em atualidade, às novas exigências da vida prática. Esta, porém, não se pode deter e, por isso, procura satisfação afeiçoando institutos já existentes às novas situações.

Fenômeno desta ordem é o que se verifica nos casos, cada vez mais freqüentes, das chamadas sociedades ficticias ou unipessoais.

A insuficiência dos sistemas legislativos vigentes, por um lado, e, pelo outro, o desejo do comerciante singular de limitar o risco na exploração de emprêsa individual, geraram o problema que tão diversamente tem sido encarado pela doutrina.

Já em várias proposições legislativas, tem-se procurado resolvê-lo em têrmos de lei, seja proscrevendo-o de modo absoluto, seja admitindo-o, com maior oú menor amplitude.

Aliás, em certa medida, já está consagrado, nas legislações mais. recentes, como no Código Civil italiano e na lei brasileira de 1940.

E' questão da maior relevância e assaz complexa.

$$
\text { - } 357-
$$

Merece detido exame e sisuda meditação.

No caso presente, conviria apreciar a proposta do Prof. Perroto juntamente com a sugestão idêntica, trazida a êste Congresso.

II) No comércio internacional nasceu, desenvolveu-se e vem se aperfeiçoando a prática da compra e venda mediante crédito bancário confirmado. Dêste jeito, logra o vendedor assegurar-se do recebimento do preço, fugindo à fé do comprador e a todos os inconvenientes a que, não raro, ficava exposto, mesmo no sistema de pagamento contra documentos.

Muito se há discutido sôbre qual a natureza jurídica de semelhante contrato.

Teorias várias urdiram-se, na tentativa de explicá-lo pelas figuras já conhecidas. Ainda aqui se faz sentir a influência da chamada lei de economia jurídica, apostada por JHERING, expediente por meio do qual, servindo-se de institutos já conhecidos, se intenta adatá-los à nova situação.

Isto vem confirmar que os fatos andam sempre na frente do. direito. A êste cabe, pois, os encarar como fundamento de suas preceituações.

Nesta ordem de considerações, propõe o Prof. PERROTTA que se considere a conveniência de trazer, para o quadro do direito mercantil argentino e brasileiro, o crédito bancário confirmado, dandolhe adequada disciplina legal.

III) Como se sabe, as sociedades por ações têm, nos títulos de participação, o instrumento técnico-legal que concretiza uti singuli o complexo de direitos de cada um dos.participantes. Essas organizações coletivas são, por motivos óbvios, dominadas pela lei do maior número.

Bem que muitas sejam as restrições que se opõem ao poder deliberante das maiorias, entretanto, várias são as hipóteses em que sua atuação é decisiva e inapelável. Exemplo disso, é a constante preocupação dos diversos sistemas legislativos por uma melhor tutela. das minorias.

A conveniência da concentração comercial e também da garantia de permanência da direção da emprêsa nas mãos dos fundadores, ou de certo grupo particular, têm sugerido expedientes diversos, entre os quais o das ações de voto múltiplo ou plural.

Neste último sentido é a sugestão em análise, na qual se recorda que, à margem da regulamentação, vem sendo difundida na prática.

Pelo que respeita ao direito brasileiro, a espécie está expressamente vedada. (Decretos-leis ns. 21.536, 15/6/1932 e 2.627, 26/9/1940, arts. $1 .^{\circ}, \S 4 .^{\circ}$ e $8 .^{\circ}, \S$ único).

Consoante o direito pátrio, estabelece-se aqui sinonimia entre. 
voto plural e voto múltiplo, embora seja, talvez, mais correto distinguir as duas hipóteses que apresentam marcadas diferenças.

Apreciando, agora em conjunto, as três proposições contidas na tese, entende a Comissão:

a) que, considerando, por um lado, o fundo comum que inspira a legislação mercantil das Nações latino-americanas e, em razão disso, também, as muitas similitudes, que apresentam as respectivas leis e, por outro lado, considerando que instituições, como a do crédito bancário confirmado, têm acentuado enderêço internacional;

b) que muito poderia concerrer para o aprimoramento das salutares relações, já existentes entre êsses países, a adoção de normas uniformes sôbre muitas matérias pertinentes ao comércio;

c) que são atendíveis, por oportunas e bem fundamentadas, as sugestões contidas na tese em aprêço, alvitra que o Congresso recomende a possível realização de uma conferência dos países latinosamericanos, para o estudo e eventual adoção de regras uniformes acêrca daquelas instituições mercantís que, mais diretamente, possam convir ao fim colimado.

Sala das sessões da Comissão de Direito Mercantil e Direito Mercantil Comparado, na Faculdade de Direito da Universidade do Rio Grande do Sul.

Pôrto Alegre, 12 de agôsto de 1950.

$$
\begin{aligned}
& \text { Hernani Estrella - Relator } \\
& \text { Júlio Cesar Bonazzola } \\
& \text { Antônio Martins Filho } \\
& \text { Henrique Rupp Júnior } \\
& \text { Ney Wiedmann }
\end{aligned}
$$

\section{DEBATES EM PLENĀRIO}

(Deixa a presidência o sr. Júlio Cézar Bonazzola, asumindo-a - o sr. Waldemar Ferreira, que acabara de apresentar o seu trabalho "sôbre "Centenário do Código Comercial do Brasil").

O SR. PRESIDENTE - Vai se discutir, agora, a tese relatada pelo sr. professor Hernani Estrella. Tem a palavra o professor Hernani Estrella.

O SR. HERNANI ESTRELLA - Sr. professor Presidente, srs. professores congressistas, meus senhores, ilustrados colegas, queridos alunos:

Como um modesto professor desta Faculdade, integrando a Co- missão de Direito Mercantil e Direito Mercantil Comparado, coubeme relatar a tese do laureado professor argentino, sr. Salvador Perrotta, catedrático da Faculdade de Direito e Ciências Sociais de Buenos Aires, que apresentou à consideração dêste Congresso o trabalho: ALGUNAS CUESTIONES MERCANTILES ANTE EL DERECHO.

Desejo salientar, à margem do parecer, que houve uma feliz coincidência entre a sugestão do ilustrado professor argentino e a do nosso patrício, laureado catedrático de Direito Comercial da conspícua Faculdade do Ceará, que nos honra com a sua presença e ilustra êste Congresso com a valia da sua cultura.

Êste eminente colega apresentou, a meu desvalioso juízo, o mais opulento e exaustivo trabalho que já se escreveu na língua pátria sôbre o tema em causa, isto é, a responsabilidade limitada da emprêsa comercial individual ou do sujeito singular comerciante, como preferiria eu, para não contrair compromissos com o conceito algo tanto equívoco de emprêsa.

Farei a leitura do modesto parecer. $(L \hat{e})$

E' o parecer que mereceu a honra de ser aprovado por todos os membros da Comissão. (Palmas).

O SR. PRESIDENTE - Está em discussão o parecer com as suas respectivas conclusões. Acontece, entretanto, que a Comissão entendeu que a primeira parte da proposição do professor Salvador Perrotta, da República Argentina, coincidia exatamente com a mesma conclusão da tese apresentada pelo professor Martins Filho.

Nessas condições, esta primeira parte das proposições dos professôres Salvador Perrotta e Martins Filho, foram discutidas conjuntamente. A Comissão chegou, neste particular, à seguinte conclusão:

"Conclusão: A Comissão aceita, em princípio, a conclusão da tese do professor Martins Filho, que é igual à tese do professor Salvador Perrotta, "emprêsa individual de responsabilidade limitada", mas recomenda que o assunto seja estudado e resolvido de molde a assegurar convenientemente os direitos de terceiro".

Foi esta, em resumo, a conclusão aprovada pela quase unanimidade de votos, porque houve um só divergente, que foi o meu, nestes têrmos: "Louvo o trabalho do professor Martins Filho, sôbre emprêsa individual de responsabilidade limitada, mas divirjo de sua conclusão, parecendo-me que a lei não deve sufragar tal instituto antes de tomar medidas que tutelem o crédito. Não compreendo que se limite a responsabilidade do comerciante sem que também se limite as suas possibilidades de contrair dívidas. De outro lado, não compreendo que se outorguem aos comerciantes vantagens de 
que não gozam os não comerciantes, que exercitam atividades econômicas de maiores riscos, como por exemplo, as agrícolas".

Eis a conclusão que está em debate. Darei a palavra a quem dela quiser fazer uso.

O SR. HERNANI ESTRELLA - Peço a palavra, sr. Presidente.

O SR. PRESIDENTE - Tem a palavra.

O SR. HERNANI ESTRELLA - Eu votei de acôrdo com a maioria, no sentido de que a proposição em causa devia ser oferecida, recomendada como objeto de legislação futura, com as ressalvas constantes da conclusão do parecer. Mas desejo esclarecer - e isto já fiz pessoalmente ao eminente autor da tese - que aceito esta conclusão com abstração da palavra "emprêsa". Eu não desejo contrair nenhum compromisso, nem mesmo fazer nenhuma insinuação ao legislador futuro, que deva legislar a respeito da emprêsa no sentido de "entidade".

Esta ressalva já tive a lealdade de explicar ao ilustre autor da tese e eu a mantenho. Era o que desejava dizer.

O SR. JOSÉ LUIZ MARTINS COSTA - Peço a palavra, sr. Presidente.

O SR PRESIDENTE - Tem a palavra.

O SR. JOSÉ LUIZ MARTINS COSTA - Sr. Presidente. Foi com a maior atenção que li o brilhante trabalho do professor Martins Filho. Fiquei verdadeiramente encantado pela maneira segura com que êle expôs a sua tese, e os conceitos interessantes que emitiu na sustentação da sua proposição.

Devo, entretanto, fazer alguns reparos com relação às conclusões. S. Excia. parece que sustenta que a responsabilidade limitada da emprêsa deve derivar necessàriamente da personalidade jurídica da mesma. A meu ver não seria possível chegar a esta premissa, porque, dada a natureza do patrimônio, como verdadeiro atributo da personalidade e sua natureza indivisível, de tal forma que se transfere pela morte ao herdeiro, não compreenderia essa responsabilidade limitada sem a premissa da personalidade atribuída à emprêsa. Mas, aqui, exatamente, está a dificuldade que se me apresenta: - dar personalidade jurídica à emprêsa me parece de certo modo anômalo, data vênia, porque a personalidade jurídica sem o fim coletivo não me parece realizável. Pelo menos êsses são os conceitos clássicos que fundamentam êsse Instituto: vontade coletiva, órgão coletivo e fim coletivo. Com relação à vontade e a respeito da fundação, como que há uma ficção: a vontade do instituidor operando como estipulação em favor de terceiros, mas sempre o órgão coletivo e o fim coletivo se manifestam.

Quanto às demais figuras da personalidade, sempre vamos encontrar êstes três requisitos: vontade coletiva, órgão coletivo e fim coletivo. Ora, relativamente à emprêsa particular não encontro êsse requisito, que considero fundamental, essencial, na personalidade jurídica.

Gostaria de ouvir o eminente professor a respeito desta dificuldade, para, se possível, aderir, com a maior satisfação, à sua conclusão.

Era o que eu tinha a salientar. (Palmas).

O SR. MARTINS FILHO - Peço a palavra.

O SR. PRESIDENTE - Tem a palavra o ilustre professor.

O SR. MARTINS FILHO - Oportunamente, quando for submetida à discussão a minha tese, que apresenta tantas afinidades com a do professor Perrota, responderei ao dr. Martins Costa, aduzindo os argumentos que parece confortarem a meu ponto de vista. 